

\title{
'Structure, Image and Ideas at play': A revisitation into the select Medical thrillers from a Grotesque lens
}

\author{
Jasmine Fernandez* and Amarjeet Nayak \\ Department of Humanities and Social Science \\ Indian Institute of Technology Indore, India \\ *Corresponding author: Jasmine Fernandez \\ E-mail: jasminepf6@gmail.com \\ Address: Indian Institute of Technology Indore, Room No. 106, Workshop Building, Simrol \\ Campus, Khandwa Road, Indore - 453552 (MP), India
}

\begin{abstract}
Medical thriller is one of the bestseller genre fictions among the popular fiction category in the contemporary times according to publishers and booksellers' list. In spite of that fact, it has been relegated to the margins of literature based on the academic critique of being 'low literature' and also as an embodiment of clashing bioethical facets that perplexes the reader's mind. Against this grain, this discussion attempts to argue that medical thriller is a significant contribution as a genre and a cultural phenomenon, primarily drawn from a grotesque lens. Grotesque in these novels are displayed as a 'play' in its various representations, engagements, use and effect of the techno-driven medical culture which Frances S. Connelly asserts as very much intrinsic to the ideation of grotesque in The Grotesque in Western Art and Culture (2006). Such a stand engages the reader enlightening with some insights about these novels which have received a blind spot from the earlier two critiques. Besides, giving insights of the insider and outsider perspective, the affectation on the readers resembles the distorted art of the grotesque. The distorted reality/view displayed by the novels intend to observe the reality of the real in its various manifestations which the paper studies as a technique of grotesque aesthetics reasserting its significance.
\end{abstract}

Keywords: significance; medical thriller; genre; culture; grotesque; play 
Whatever has been said of the medical genre can be premised as either negative/ reductive, taking into account the scholarship of the works which have already been done and is indeed the one that necessitates this study. We have an overt dismissal of the genre as literature of merit that conclusively places the works on the pedestal of 'low literature' on the one hand, and on the other appears the strong criticism (bioethicists) as a breach of ethical values which support for its reductive assumption ${ }^{1}$. Either way, the genre is seen as one inhabiting the realm of low literary profile. At this critical juncture, it is also interesting to note that the genre continues to be a popular bestseller and on the top list of publishers and bookshelves which is a contradictory phenomenon relative to its academic dismissal. This discussion therefore takes us through a framework of grotesque theories in the select medical thrillers Coma (1977) by Robin Cook, and Harvest (1997) by Tess Gerritsen that opens up some telling aspects of the works and calls for a revisitation. The theme of organ harvesting helps to narrow down from the huge collection of medical thrillers as well as give a better space to discuss and enlighten on the significance of medical thriller genre keeping this point of view. In spite of its problem of being read contrary to its writers' intention and understanding of this genre as ascribed by scholars like Catherine Belling, there is a dearth of scholarship in these lines ${ }^{2}$. Hence, we can safely say that continued disavowal of the texts emanates from the assumption of the work as being a straight forward piece. Also, studies reveal that critics have acknowledged the medical world as exaggerated and unreal, but nevertheless the distorted world represented by the texts, dovetail the language of medicine, a cultural understanding and transmission of the body which is incongruous with the understanding of the popular imagination is never scrutinized.

While in pointing out the works as corrupting the reader's perspective of the medical world, the early critiques come in short of noting that the works' display a distorted medical world acquired from 'play'. 'Play' resorts to distortion, incongruity, ambivalence, confusion, fear and horror inspired from grotesque aesthetics in order to accommodate the world as not just a heterogeneous space but also the competing survivalism, a reality of the real $l^{3}$ in the contemporary world.

This interpretation comes through as medical thrillers are a derivative of urban legend narratives. It is a requisite to acknowledge that a clear and certain interpretation of the texts cannot be conceived of in the meaning making mechanism. In the event of being such a narrative, these stories speak of cultural anxieties and fear of medical intrusion 
and intervention that accumulate as sediments in a progressive society against the backdrop of a cultural stagnation of medical ideas about bodies, their performativity and relationships. The clash between normative and progressive ideas evolved results in a grotesque reality, a reality that seeks to draw many in-betweens, liminal states and events. This distortion of view is represented by accommodating exaggerated versions of medical progress with characters, situations, settings and events that contribute to highlighting these neglected spaces which keeps it apart from other literature that never tread this dangerous path. In the prevalence of viewing everything as grotesque - a sort of cheapening task to the work's literary value and John Frow's assertion that genre fiction is a literature that represents 'a relationship between textual structures and the situations that occasion them' (Frow 13), this paper seeks to highlight the importance of grotesquery which in turn makes medical thriller genre significant by putting representations of medical culture into a sort of 'play'. Medical thrillers, being of the category of professionally-based fiction inform and articulate 'about and to' the core conventions of insider/outsider view of the medical profession by engaging the reader in the particular fictive world in the currency of the historical situation that germinates the narrativization of the genre.

As a framework for the study, the novels are closely examined as an aesthetic category of grotesque, a style that is quite interlinked with the Renaissance after the discovery of the caves uncovered from Nero's Domus Aurea. This precisely draws an understanding of the grotesque as a play of structure and content (topos). The second approach grasped for the departure of the essay is to envision it as a cultural phenomenon, a term Frances S. Connelly uses in the work The Grotesque in Literature and Art: Image at Play (2006) and finally Shun Liang Chao's employment of the grotesque as a metaphor in Rethinking Grotesque (2010). Here in this discussion we apply it as a cultural metaphor for it changes from culture to culture and era to era, an idea Harpham asserts in his essay 'The Grotesque: First Principles' (1976). ${ }^{4}$

A focus on the literary techniques, narrative style and representations of medical culture suggest that a 'play' underlines the novels at the level of plot, characterization and idea of the medical culture. At the level of plot, the play lies in the suspenseful narration of organ harvest. Cook explores the organ heist narrative plot that occurs between the famous Boston Memorial Hospital and Jefferson Institute of Medical Sciences. This naturally pushes forward a 'play' within characters and the general idea of medical institutions. Susan Wheeler, champions as the stereotypical 'doctor-saviour' unveiling 
the mystery of a series of comatose death. In the journey, the functionalist doctorpatient relationship is distorted and gives a perspective of 'doctor-murderer' types such as Dr Goldberg and his accomplices. In the same way, Gerritsen pulls out a story of organ heist traversing through a hunt for donors. The underprivileged and anyone against the scheme are targeted as organ donors for rich patients like Ann Voss. Creating a dystopian medical culture, the narratives proliferate throughout as a glimpse of idea, structure, image and language at 'play'. The prologue in Coma issues as an impending disaster and omen that lends suspense and tension.

Nancy Greenly lay on the operating table on her back, staring up at the kettledrumshaped lights in operating in Room no.8, trying to be calm. She had several pre-op injections, which she was told would make her sleepy and happy. She was neither. Nancy was more nervous and apprehensive than before the shots. Worst of all, she felt totally, completely and absolutely defenceless. (Cook 1)

True to the genre category we notice our works uphold the thrill and work to contribute towards more than suspense and thrill as the title enunciate. This is invited from necessarily reading the works as a grotesque piece wherein the author's intention of the works as being a source of reliable information and a complex database of medical culture. Furthermore, giving multiple perspectives, both insider and outsider views, that points to many other hidden aspects often from a 'doubling' which in Le Byron Jennings ${ }^{5}$ opinion helps to perceive the coexistence of events and characters as in our own world. This is in keeping with the grotesque world echoing Kayserian grotesque as well as the real world.

As there is a 'play' element, it is important to specify that other forms of grotesquery exist as central to or derived from it. The grotesquery proliferates as in the literal application of the organ harvesting and in its symbolic application which helps in the perpetuation of the process. The idea of organ as 'gift', machine parts and 'waste' metaphor are the commonly employed vehicles to encourage the donation process. The idea of formulation of organ harvesting as evincing meaninglessness echoes the heist thrillers. For in the process, functionalistic notion of medical culture is breached, as organ theft and murder are themselves rendered meaningless and absurd as one patient is murdered to transfer life to another. This meaninglessness, anxiety and horror are revealed by Katzka when he reveals the murder of Dr Levi. 'Dr Levi never hanged 
himself said Katza... We have found something on toxicology... 'In his muscle tissue. They found traces of succinylcholine"'. (Gerritsen 416)

Once we see that organ heist theme to be grotesque, it is necessary to know originally there occurs, no consensus in the idea of any theme as inherently grotesque. But it can be delineated that organ harvesting is considered so only from the purview of deviation from the cultural idea of body integrity and also the incomprehensiveness in absorbing organ legging that is retold in various urban legends. In this, we can say that the 'play' from organ heist theme is directed at representation of bodies(in)parts, the hospital as an anthropomorphic entity with its specific jargon that challenges the passively objectified medicalized body, the ways in which the concepts and constructions of the body shape the people's experience of agency and objectification, the function of body(in)parts within medical culture and society, and also how the metaphors and models of the body are used to understand a medical phenomenon like organ harvesting. The grotesquery also permeates to the level which includes representations of patient care giving an insight into some of the diagnostic practices, surgery, and anatomy and how medical research flourishes within its ecosystem by contradicting with the popular notions of patient care and understanding of human anatomy.

Evidently, the textual analysis suggests that the prevailing anxiety, thrill, suspense and ambiguity emanating from the novels are an aftermath of a cultural consciousness that is aware of breaching medical technology upon the characters. Thus the initial blind spot reserved towards the grotesque mode comes alive as a presence and it is noticeable that not only the plot, theme and issues generate 'a distorted world view and alienation' ${ }^{6}$ of the normative world but the reader's cultural background and knowledge of medicine from a lay perspective contributes in shaping a distorted perspective. For example, a reader from the third world country, exposed to organ theft legends and media news coverage receives the narratives as a strategy of a new form of colonization unlike a western counterpart who interprets the works from a slightly different perspective wherein the understanding shifts to the significance of organ donation in context with a dearth of organs for transplantation. Thus funnelling through an assemblage of disparate images, ideas, metaphors and structures, the novels function to put meanings and structures into 'play'. The different takes on the theme of organ harvesting like the focus of difference or subversion of the issue of organ harvesting by different readers justifies the writer's defensive take on the works against the harsh criticism from critics and commentators. One such example can be found in Coma (1977) that explains the 
writer's complete denial of charges against misleading the popular imagination by scholars of bioethics and doctors equally. 'This novel was conceived as an entertainment but it is not science fiction. Its implications are scary because they are possible, perhaps even probable.' (Cook 361) Such an assertion by the writer demands a rethinking of medical thriller's critiques and therefore demands 'revisitation' into the fictions for its literary worth. It is probable that critics have indelibly missed out the grotesquery which has a presence in the whole work, not just the structure, but in the form and content as cited earlier. However, the literary omission and historical trajectory can be a subject of another paper given the limitation of this paper the study compels us to explore the grotesquery in our works and thereby draw its significance in terms of a genre and a cultural phenomenon limiting to perceive the element of 'play' in its various manifestations. We also say that criticism against the genre primarily emanates not only from the medium but also its mediation, reception and response which corroborate with the concept of grotesquery.

Before going further, it is instructive to ask here, 'what is the grotesque/grotesquery?' As is the case with any literary theory that has a complex historical and cultural baggage, the concept of grotesquery shows traces of the problem of evolution. This brings to mind an essay of Thomas Mann, 'Past Masters' where he brings forth the idea of modern art as something existing between the categories of tragedy and comedy. Through such an idea he means to stress on the reality of in-betweens, categories that often overrule and trespass the boundaries. It occurs that, then the aesthetic of grotesque which he defines as something similar. Mann therefore likened tragic-comedy to grotesque, as it changes from era to era and form to form. This historical point of view suggests grotesque theories as not one thing or another but something which are like poles in a continuum but having crossovers. Kayserian and Bakhtinian studies indicate this concern and complexity of the grotesque. Though, neither of them agrees on the others' point of view, it can be seen that at various places both speak of the same thing but in different contexts. This sums the grotesque to be a juxtaposition of incorrigible images, ideas and structures to subvert, to question normativity and also incorporate fantastique experiences or a 'willing suspension of disbelief' in Coleridge's terminology. This in turn calls for a suspended disbelief in the world in order to counter the demonic forces residing in the Kayserian grotesque world or to counter the hierarchical system as in carnivalesque grotesque. In either case the grotesque is a liminal category, a hybrid or metamorphic character. A few of grotesque characters can 
be sighted as in the mythical characters like Centaur, Ganesh, Android, Frankenstein's monster etc. which are recognized in a suspended time and space. However, the modern context has drawn these characters from their niche into the outside world unlike the previous periods where it remained hidden in the unconscious. The space occupied by these characters becomes a chaotic world, alienated and distorted, a representation of which is captured by Robert Penn Warren in his Ballad of a Sweet Dream of Peace (1975). He describes the grotesque in the following terms:

The grotesque is one of the most obvious forms art may take to pierce the veil of familiarity, to stab us from the drowse of the accustomed, to make us aware of the perilous paradoxicality of life. The grotesque evokes dormant emotions, particularly the negative ones of fear, disgust, revulsion, guilt. But it is close to the comic, and in it laughter and horror meet.

Such a chaotic world is horrific and confusing for the reader as it turns inside-out various lurking realities along with anxiety and fear as response. The projection of the medical world as a concomitant space of both good and evil is in order to grasp the reality of the actual world against the fantastique world often quoted in other fantasy/science fiction genres. To comprehend the in-betweens, an inclusive space where the contemporary techno driven possibilities of evil and good can take place becomes the essence of the medical thriller genre. In neither assuming the position occupied by the church once, nor for scientific progress the works invite varied interpretation in assuming a middle path which is culture specific and grotesque like. If one were to draw criticism against the genre for its violent entertainment as Maria Tatar notes, then it is primarily as a 'violent or anxious entertainment to discipline people'. (Tartar, 78) Particularly, this insight is reminiscent of Kayserian grotesque which conceives grotesquery as not an escape but a realistic way of coping with the often ignored demonic elements of reality ${ }^{6}$, the process leading to the divergent resolutions which is indeed a form of disciplining. When we contextualize Clark Mc Cauley's \& Dolfman Zilman's suggestion about the attraction of violent entertainment they state that one may be attracted to something and at the same time experience many emotions like disgust and anxiety without enjoying, answers to the wider readership of the medical thriller. The grotesquery in the violence arises from the conflict and an affect/acceptance of the issues related to not only the debatable scientific procedure such as organ harvesting upon the contemporary society but also other relations and workings in context with a technologized medical culture. The clash of normative 
understandings of culture and society with scientific understandings therefore impinges upon the psychological and cultural values. The novel's partially fantastical engagement and partial reality bespeaks of a reality that is multi sided or diffused clearing the veil of utopia. In the representation of doctors like Susan Wheeler (Coma) and Dr Abbey Di Mateo (Harvest) along with Dr Mark Holleman, Dr Goldberg and Dr Dutton enlighten us with diverse medical characters. And our contention in this study is that the reader response of the novels as an inflection of the grotesque, in the changing structure of medical culture, language and the normative ideas of body integrity and the identity of an individual in modern medicine hold true ${ }^{7}$.

Within the heterogeneity of academic approaches, functionalist approach in medical sociology and history of social medicine view social relations in health care as a product of a consensualist society, where social order and harmony are preserved by people acting in certain defined roles and performing certain functions. The implication is that the doctor works for the betterment of the health condition of a patient, the crux of modern medicine. It also tells about the emotional relationship between patient and doctor, the needs, the drives both conscious and unconscious, that underpin it. (Lupton 1977) But the problem of such a stand is that it marks out 'social deviance' from the normal and works like how the church once did. (Talcott, Parsons cited in Lupton) The idea perpetuated in this context is that 'ill people must want to try and get well, if they do not, they can be accused of "malingering" and being sick is defined as being in need of medical help, to return to "normality". The sick must put themselves into the hands of medical practitioners to help them get well again.' (Parson 1951a, 1957b: 151-152). Functionalists suggest that the doctor-patient relationship is unequal, harmonious and socially beneficent. The idea naturally places the doctor on a higher pedestal with omnipotence not without the problematic of shakiness and slipperiness that accompanies such a key position. The advantage to delve into the interiors of the human body is double edged as certain communities posit such an intrusion as a taboo where the body is considered integral, with a boundary and identity. The problem worsens in a technologized and advancing medical world where philanthropic ideologies are replaced/ evolving more towards a political economic perspective. The original philanthropic assumption gets distorted in the mediation of a commodification trend resulting in anxiety, horror and ambiguity in the idea of doctor. This particular altered reality centers the fictions and especially in the context of organ black market. Many a times, at such a juncture in the pretext of assumed (dys) function ${ }^{8}$ of the body, body 
accessibility becomes a potential space for malpractice ${ }^{9}$ and threat as observed in Harvest (1999).

He was proving with every slice of his scalpel. Tarasoff assisted, positioning retractors, clamping bleeders. It was pleasure to work with such young healthy tissue. The woman was in excellent condition. She had a minimum of subcutaneous fat and her abdominal muscles were flat and tight- so tight that their assistant, standing at the head of the table, had to infuse more succinylcholine to relax them for easier retraction. The scalpel blade penetrated the muscle layer. They were in the abdominal cavity now. Tarasoff widened the retractors. Beneath a thin veil of peritoneal tissue glistened the liver and the loops of small intestine? All of it healthy, so healthy! The human organism was a beautiful sight to behold. (Gerritsen 503)

Here, Gerritsen derives the textual play of the image of doctor from 'the conflict of interest between doctor and patient, as an expression of struggle for power, which may be explicit or implicit and involves negotiation and manoeuvre at every step in the medical encounter.' (Gerson\& Strong 1976, 1979:7) However, it turns out to be diabolic at the hands of Tarasoff. As is the case with Coma, the admitted patients are Carbon monoxide poisoned and availed for organ harvesting while in Harvest after cell typing or tissue matching a needy recipient, the orphan children like Stephan and Aleski are harvested for rich patients. This idea complicates and generates the response of a grotesque because of its complex language and struggle with normative cultures and religious understandings. The notion of reassembling body parts from a dead or living patient has not only a strong religious confrontation across communities but also cultural anxiety based on the idea of integrity with the soul and body and also anxiety associated with murder of a living person in dearth of organ for transplant or acceptance of a foreign body.

\section{Representations of medical culture: a distorted, ambiguous and incomprehensible world of medicine}

We have two competing issues when we examine the professionally-based nature of the thrillers and the entertainment content as Cook emphasizes: 'I think of myself more as a doctor who writes, rather than a writer who happens to be a doctor ${ }^{10}$. Tess Gerritsen, in one of her interviews opines that though some efforts are being done in keeping with the 
idea of not confusing the reader by giving exact details of medical representations, most of the representations are true to medicine. Therefore, the fictional account of medical procedures is credible though the plot is mostly fiction. Some writers' such as Michael Palmer agree that they write not only for entertainment but also '....to present, without resolution, issues of social and ethical importance' (cited in 'Doctored fictions' Palmer, 501) Thus we can say that medical thrillers are a mixture of technical details, medical facts, ethical issues, cultural clashes and suspense.

\section{a) 'Play of structure, ideas and image': Medical world as grotesque}

We have already understood the play element as the crux of the medical thriller's suspense and thrill. 'Play' expands to its morphology which includes the representations of spaces like the hospital, its concrete construction, along with the whole idea associated with hospital and ideas of people within that environment, their relationships and images of various medical procedures, culture and language used for the promotion of these. Generally, medical space is a closed one as its workings are not privy to popular imaginations in the same way as professional space is likely to be. It is not astonishing to see that such a setting therefore prevails upon a register, culture, working and protocol of its own. However, for the public this space is understood mainly from the cultural understanding as 'a place where people who are ill or injured are treated and taken care of by doctors and nurses' as explained by the Cambridge dictionary. This unchartered territory thereby is a curious station because of its inaccessibility and complexity.

The fictional accounts of hospitals like Boston Memorial in Coma (1977) or the Jefferson Institute of Medical Sciences, or the Bayside Memorial and the Massachusetts Med School in Harvest lie in line with such accounts. Elaborating on the structure of the Boston Memorial a similitude with the gothic castles and palaces of medieval times is drawn. The Bayside Memorial too elicits a similar reaction by specifying its endless number of rooms and unknown spaces. This positioning not only creates an ambience of fear associated with the caves/dark places. The cave, 'grotte' in Italian, in a grotesque study assumes significance for its rich associations with the cycles of fertility, rebirth and death. This assumption enables to view the hospital as a potential site of events in many ways. The second impression is that of an animating presence- one that is full of life, with an anthropomorphization of the whole buildings as perceptible throughout the 
narrative which clashes with the normal understanding of the structure as non-living. The narrative architectural description therefore shifts the reader's thoughts to some spirits still left within the buildings. This setting not only sets the stage for the happenings that are later to be uncovered but makes it a fertile space to infuse the reality of the real. Boston Memorial Hospital shifts in perception from a normal space to a gothic claustrophic one and harbingers some confusion in the first appearance. This collates with the narrator's specification of the same as 'certainly not an architectural landmark', 'disproportionate(ly) large number of architects' and echoing that the 'central building is attractive and interesting'. On contextualizing temporality 'was constructed over a century ago with brown stone blocks and carefully fitted together with skill and feeling' aid in relating the building to the gothic and also to ancient structure. 'But the structure is inconveniently small and only two stories tall.' (Cook 20) After creating a mental imagery of a gothic structure, the reassertion makes the reader affirm their initial image relation. 'It was designed with large general wards now outmoded. Hence the present day practicality is miniscule. Only the ooze of medical history which permeates its halls keeps the wreckers and planners at bay'. (Cook 21) When the narrator again insists on the details of the architecture 'The innumerable larger buildings are studies in American Gothic. ... There is no doubt an ugly combination of buildings, except perhaps for a few research buildings. Those had architects and money to burn.' (Cook 21), it is meant to reawaken the reader to the grotesque existence and presence of the hospital. The narrator's own expression that only a 'very few people notice the appearance buildings. The whole is larger than the sum of its parts: perception is too clouded by the innumerable layers of emotional response' along with the assertion that 'the buildings are not buildings themselves. They are the famed Boston Memorial Hospital containing all the mystery and wizardry of modern medicine. Fear and excitement intermingle in an ambivalent manner as the lay people approach the structure. And for the professional individual it is the mecca, the pinnacle of Academic medicine' (Cook 21) calls for a perspective in grotesque. The narrator does not stop with this, but explicates further that the hospital functions as a labyrinthine cave both metaphorically and literally with mysteries of birth, death and rebirth. 'Having been built in haphazard spurts, the Memorial was labyrinthine. I'm not sure I'm going to like this place'. (Cook 28) Being a constant presence in all the novels this space invades the minds of the characters and readers in different ways often resulting in trauma, death and rebirth. In Coma, for instance most of the times, the 
patients are seen to struggle to overcome its (hospital's) influence or are influenced by it resulting in alienation, sometimes psychological and at other times physiological. This influence of the hospital is seen in Nancy Greenly in Coma. Before her visit to the hospital, she was sick, bleeding excessively, yet she had a life. On reaching the hospital she becomes a donor of vital organs due to the malpractice at the hospital. Moreover, when viewed from the popular perspective, it can be seen that there is a transformation from otherwise healthy (live) to diseased that gets mediated by the hospital which results in her final state of comatose and rebirth into a bank of vital organs. The same can be said of Dr Abby DiMateo in Harvest who not only flourishes initially as doctor but later on loses her position and finally becomes a prey to organ harvesting due to her discovery of malpractice within Bayside Memorial. Not to mention, the hospital transforms her into a bank of organs for transplantation. Whether it is Nancy Greenly or Dr Abbey Di Mateo, when they enter the hospital, they become vulnerable and exposed to the hands of surgeon's knives. While in Coma it was excessive Carbon monoxide that transforms Nancy Greenly and other patients into a comatose state, in Harvest it is excessive sucynocholine that transforms and prepares live patients for heart transplant. Amongst other things, the text also draws our attention to the experience of being a patient. Using an omniscient point of view, the narrator transforms the experience of the patient through the characterization of Nancy Greenly who is admitted at the doctors' chamber for examination. It starts off to capture the emotional trauma and dislike of being a patient which substantiates my initial observation of a grotesque approach. She is observed to be 'trying to be calm' at the operating table facing the large kettledrum shaped lights. The narrator knows that 'she was given pre-op injections to make her sleepy and happy. She was neither.' (Cook 1) On the contrary, she was observed to be more 'nervous and apprehensive before the shots.' It could be seen that 'she felt completely and absolutely defenceless.' (Cook 1) At the same time it could be divulged that 'she felt embarrassed and so vulnerable.' (Cook 1) The patient's psychological conflict comes through as the narrator captures her emotional preoccupation and its botheration. By describing the edge of the white linen with a tear and frayed at the edge, Nancy's vulnerability, defencelessness and subjection of being a patient is absorbed. Not only is this an insight into her cultural upbringing, the need to have a private self that is separate and hidden from others also projected. Another way of looking at it is the incapacitance of the patient on the operating table against the medical gaze, a tug of war between the patient to cover up her identity and the objectifying medical procedures 
that tries to subject her to its scrutiny. 'Under the sheet, she had one of those hospital gowns which tie behind the neck and descend only to mid-thigh. The back was open, other than that there was only the sanitary napkin which she knew was already soaked with blood.' (Cook 1) Usually, such an image should educe desire but instead of it, it ushers disgust, anxiety and fear of a portending disaster. This also draws the reader's empathy which is evoked by the use of the phrase "soaked with blood" at the end.

In conveying her ambiguous mind 'she (Nancy) hated and feared the hospital at the moment and wanted to scream, to run out of the room and down the corridor. But she didn't. She feared the bleeding that she had been experiencing more than the cruel, detached environment of the hospital; both made her acutely aware of her mortality, and that was something she rarely liked to face.' (Cook 1) The medical atmosphere of aloofness and dread is well established. Now that the competing emotions 'of fear' and 'cruel' and 'detach(ed)' project to the hospital as a niche of the grotesque and gothic as initially suggested in the essay. A suggestion of an incantation of the gothic and uncanny atmosphere surrounding the hospital is evoked by narrating 'there were no voices, just the sound of the machines and the wind' (Cook 2). Uncanny, to Freud is 'the class of terrifying which leads back to something long known to us, once very familiar.' (Freud 2) He used it in the sense of the German word unheimlich ${ }^{11}$. By suggestion of such an environment, the story accompanies a portending ominousness of the place as it progresses. Given this understanding, an investigation into the etiology of the name Boston is useful as there lays a strange association with the city of the same name. The city of Boston is a transferred name from Boston Lincolnshire, England named after a patron saint Botwulf from old English - a patron of 'travellers and farming'. The location of the hospital in Boston named after the city then rightly agrees with the kind of activity in the hospital, i.e. organ harvesting- a close metaphor to farming, an activity which Freud would rightly term uncanny or many aestheticians would term grotesque. That said, it can be said that the novel's deliberation in employing the same hospital after the town is not only judicious but indicative of its ominous connections. Its employment in the novel is to signify and also to contradict the normal American association of the hospital with the end of life treatment and saving lives. Against this backdrop it is interesting to note that the activities within the hospital and the fluorescent lights spread over every inch of the OR area makes one recall the dread of organ harvesting activity. When this imagery is paralleled with the surgical activity which the narrator tells, it heightens a sense of tension coupled with the 
note on 'the patient fetching, the prep, the scrub and the induction under the anesthesia had to be completed before 7.30 ' ticking the time span of the activity (Cook 2) which is suggestive of organ harvesting every hour of the day. Not only that, in the dissemination of the idea of organ transplantation a metaphor employed for harvesting and metaphor of greenery, of something as a large production activity is highlighted. Studies reveal that such transferred metaphors reduce the hostility towards the profession and activity which would otherwise invite problems. By describing OR no. 8 and omitting its specialty in the introduction, the narrator seeks to draw suspense, (a typical technique of detective stories and films) by ellison, a simple technique of thrillers. This strategy operates to perceive OR no. 8 without giving the slightest idea of focus. It is also interesting to note that specifying Nancy Greenly is operated in OR no.8 almost reads like a portending disaster to be awaited. While it is perceptible that words like 'a bother, gigantic nuisance' suffice to tell about the inconvenience and also irritation at having a profuse bleeding and also the stress on Nancy, an incident from the work 'it had come at the most inopportune time' (Cook 1), also reiterates an ominous overtone. Along with these citations, the narrative takes an objective view and analyses both the psychology of the physician and the patient evoking the confusion, disharmony, ambiguity, comic and an element of terror associated with this grotesque situation. The patient is ingrained with the hospital as her health leaves her with no choice. Not only that, for a simple medical condition such as excessive bleeding, she has to die and leave her body(in)parts for use by other recipients. This process as a whole is echoing the ritual of Bakhtinian carnivalesque in the fact of rebirth, however there is no comic laughter associated with this procedure yet there emerges a laughter that is cynical. The patient dies and is reborn as her parts generate life to another recipient continuing with a new life. The consequence of blending with the hospital in this way is the gradual loss of personal identity and autonomous action. The disassembling and assembling process itself is grotesque for two reasons. Firstly, the unconscious need to survive against another's life is lying in sync with the Kayserian idea where grotesque are the inherent demonic forces residing within the unconscious. Secondly, the reassembling process generates rebirth or new life which is carnivalesque in trend. Thus the literal harvesting process is inherently grotesque. The next issue accompanying with reassembling is the cultural idea of identity. If we are to assume identity as embodied, it is highly problematic for it raises questions of which identity the person possesses. This problem has been critically examined in stories of dystopian 
versions which manifest the clash of double identities and the fear accompanying it.

It is not without concern that the niche of the hospital is represented in its unremarkable surroundings. By projecting the elevated rusted highways and the other a housing project for low income families and the front of the hospital housing the Boston harbour with 'water like black coffee and sewer gas', the setting echoes the grotesquery. (Cook 28) The intermingling of opposite worlds suggests its interactions. The interactions come in the form of patients entering the hospital eventually getting cured or dead or in the rebirth as in the two novels. This locale echoes the grotesque mode of combining incompatible settings, clean hospital surroundings juxtaposed with dirty outskirts. This idea, if further extended, can be seen as a space where purity and impurity are two sanctuaries like the medieval art where a clear demarcation is brought between Christian ideologies and pagan belief systems. However, it would be unfair if the text's interpretation does not include the subversive mock intended. Firstly, the structural demarcation is then a physical attribute of the internal and external tensions coexisting. The clean environment may not always be an indication of clean dealings or workings within the hospital. That said, the dirty environs outside the hospital are not indicative of corruption and other malice. The graphic narrative of the settings is a mock and a call for (re)vision of our informed understandings.

\section{b) 'Play of ideas': Relationships as ambiguous and distorted}

As the environment cannot be stirred clear of its influence upon the medical professionals and patients alike, even the relationships become ambiguous and distorted. As the adage goes like this 'a healthy relationship in a healthy environment', we can see that being reflected in reality. Founded and sustained on highly economic incentives and cultural values, the philanthropic element diminishes and a career oriented, ambitious and competitive world comes into being. While the doctor-nurse relationship is a highly debated and overlooked area in various fictions, the medical thriller differs from them in many ways. This does not mean that the stereotypical depiction of doctor-nurse relationship is completely not found. The stereotypical relationship is primarily joked about for its sexual liaisons and hierarchy. Under such an understanding the nurse is portrayed as the butt of all the frustration of the doctor. A typical one can be observed in Coma: 'the circulating nurse had broken into tears before the case was over and had to be replaced.'(Cook 36) However it is interesting to note 
that with the type of patriarchal framework at most levels, there also exists a rebuttal within the medical culture in the medical thrillers as one realizes with shock that the female nurses act as bridging the gap of work pressure and often turn out to be the heroines who discover the maleficent corruption in the medical institutions. In the wake of feminist voice that asserted its significance, this portrayal is suggestive of changing cultural, social and economic values. Along with this, there is a constant clash with the earlier cultural values that view women as creatures of nothing more than beauty and body. Mark Bellows' shakiness on viewing Susan Wheeler is a case in point. 'He was not prepared for the attractiveness of the girl'. (Cook 32) The tension of beauty and brains is evident in several instances in all these novels. By combining a beautiful woman with brains, the normative idea is questioned and subverted. The cultural load forbids such a disparate combination as it breaches normality. Not only that, the idea of ugliness with brains is also questioned by portraying someone like Susan Wheeler and at various places she is a marginal grotesque presence of her times. Furthermore, her marginality pervades all through her work space primarily in the construction of doctor's lounging room especially designed for men. The women were predicated to work as nurses, as a helping hand, a structured design of patriarchy and her choice of being a doctor makes her an uncalled grotesque presence.

The next important relationship is obviously nurse and medical student relationship. Contrary to the popular notions of nurse-doctor relationship, the medical students are not really to be seen as on the higher pedestal of hierarchy. The narrative articulates the medical students as a sort of nuisance and trouble. When the medical students approach the nurse on duty to know the exact room where their supervisor had called for a meeting they experience an unwelcome insult. She says, 'You're not going to believe it, Nance, but today are going to be one of those days. Guess what we got/...We got ourselves a new group of green med students.' (Cook 30) This incongruous or distorted representation incurs a grotesque reality unlike the ordinary idea or even Bellows' idea as a common man: '...will introduce you to the nursing staff who will be thrilled to meet you' (Cook 35). Against this notion, when Susan explains their reception, Bellows' answer 'nurses have learnt that new housing staff is probably more deadly than bacteria and virus put together. So don't expect to be greeted as savior's here, least of all from the nurses' (Cook 35) insist that distorted representations are for imparting different sides to the medical culture and impart the insider view of the culture. The doctor patient relationship is also a very precarious one for it sustains the whole medicalization 
process. The working relationship accrues from the demand of the patient and also the doctors' use of his skill and his means of livelihood. At this crucial stage, it goes without saying that the norm of this relationship is one of hierarchy, where the doctor assumes a position of being the 'savior'. Ideally, though the doctors are trained to acquire the medical gaze and take care of their patients, they are affected by a failure in their surgery or treatment. Often this frustration is let out in the form of humor that is obscene and also as anger. While the patient undergoes a lot of trauma and pain being in the hospital, the doctor is seen mostly used to the blood, the stains, and the exposed bodies and all sorts of distortions that make them not only distant but sometimes feeling less. However, we see Susan Wheeler to be an exception. Being a medical student, her experience is limited; therefore, she has not imbibed the medical gaze as Dr Major expresses very professionally 'The definitive cure for her condition was a dilation and curettage.' (Cook 4) The surgical nurse Gloria De Mateo 'regarded her with her deep brown eyes through her surgical hood and asked, are you comfortable?' (Cook 5) which is suggestive of the medical gaze. Perhaps, this quality enables her to investigate the cases and become susceptible to danger as the story ends. Thus Coma edges on the play of emotional response versus objectivity of medical science. While the patient is always submitted to the medical procedure with the only happy thought that the the whole goddamned nightmare was going to be over within an hour and her life would return to normal' (Cook 4) as Nancy Greenly thought. Sometimes the ideal notion gets replaced when priorities for the doctors change to clinical research, profit and black market. It is indeed necessary to mention that such clinical experiments become in the true sense a Bakhtinian carnival for the doctor. Equipped with the power to have access to the interiors of the body, disassembling and assembling and molding according to his surgery knife, the doctors bring about life, death and rebirth. The narrator's presentation of the anesthesiologist's obsession with 2 bromo 2 chloro trifluoromethane and his manometer that has 'an almost perfect anesthetic agent' with potential for destroying the liver (Cook 5) highlights, the doctor's obsession with power and rewards instead of the patient's belief in him as the savior. Here this grotesque satire is drawn against the doctor to show the deviances within doctor-patient relationship. The medieval image of the doctor as grave diggers and thieves can be recounted in this context for this helps in suggesting the notion of the doctor as 'thief' and 'gravedigger', unlike the modern notion of 'savior' that has been prevalent ${ }^{12}$. The doctor is seen as grotesque due to the perception he possesses as in Coma. Rightly said, not all doctors are grotesque in the 
novels; take the example of Susan Wheeler and Dr Abbey DiMateo in Harvest who risks their lives to uncover the truth about organ trafficking at Boston Memorial and Bayside Memorial, respectively. Dr Goldberg, the director of Boston Memorial (Coma) who connives and organizes organ trafficking in Coma through carbon monoxide induced comatose and Dr Mark (Harvest) can be placed on the same plane for their theft and injustice towards patients as the medieval surgeons.

Variously, account of the degree of frustration and anger that cannot be taken out, is indeed is seen to be present in different doctors. The narrator describes Dr Cowley as such '...But when things went contrary to his wishes, he was a firebrand of the most vicious nature, a seething cauldron of invective. In short, he was a juvenile in adult clothing.' (Cook 36) 'Dr Cowley was absolutely pissed and he spared no one...The anesthesiology resident had had to weather one of the worst bombardments of foul words and captious epithets that had ever been hurled over an anesthesia screen. The surgical resident first assisting had a small cut in the right index finger from Cowley's scalpel.' (Cook 36) Such examples bring out the insider account of various psychological impulses of the doctors. This picture rather than alienating the doctor from the lay imagination brings forth more humanized and real characters. Not only that, it enables to reduce the awe associated with the doctor's figure by portraying a realistic account. The narrative focus on doctors with theirs flaws helps to acquaint the doctor as one among the public reducing his divinity associated with altruism along with modern technology. The canvas draws our attention to the connection with the industrialized society that produces labors in plenty indicating the mass ritual of labor production and devaluation of human labor in general. Unlike alternative practices of medicine like shamanism or the witch doctor, Santeria or the Vodun ${ }^{13}$ practices which are often accompanied or mixed as ritual to ward off invading problems such as a disease or intoxication, modern medicine distances the human interaction even in the case of treatments. This understanding portrays the flaw and a certain anxiety that accompanies it and its impact appears in recent debates on machine versus man. Having been able to drain a greater amount of power vested in these professionals, this has helped to lighten the burden of the doctor as God. The villainous projection in the characters of the physicians emanates from such a gap and a psyche. Another way to think of is that with the aid of mechanical power doctors become doubly equipped and more powerful to invade the interiors which are not accessible to others. The characterization of Dr Stark who concocts to induce comatose in normal patients is a 
case in point. He distances himself from the patient community and is shown more to be interested in the development of research centres and technology and oriented towards economic politic perspective of the medical institution. Portrayal of characters like Susan Wheeler or Fairweather is not only an urgency to show but also to highlight the contrast the expanse of relationships and workings in a discourse of medical culture such as this. In other words, an empathetic Susan wheeler stands for the outsider who is not much emotionally entangled with power, capital and other benefits which the profession has to offer. It is very much conveying of the insider/outsider continuum of the medical space showing the play of dynamics. Not to ignore is the fact that medical gaze has not yet set in which again goes back to the author's reaffirmation and critique on the idea that the objectivized approach in medicine is not only a flaw as it brings closer to the idea of the missing gaps that is required for a personalized care of the patients. This space has opened up the possibilities for narrative medicine that brings an empathetic approach to patient community calling for more patient friendly treatments. The kind of approach such physicians as doctor Stark envision is in line with overlooking the medical thriller as a 'conscious confusion' between a moment towards a futuristic vision and a moment that is haunted by the past while capturing the present moment. And it is important to understand the dynamics of medical encounter in context with the transplant professionals against other physicians. While in the medical community, it is a highly valued, respected and highly paid vocation, in the outside world it is the opposite especially in case of a transplant specialist. They occupy a very ambiguous reception from among patient's families i.e. donors and recipients. However, this happens because of the cultural confusion that gets muddled with the advanced medical procedure. At one point these transplant officials are seen as hostile beings among donor families for the deep emotional attachment in parting with their loved one's body (in) parts that now exist as sediments. Here, then they are seen as 'butchers' as in medical culture the terminology is applicable to surgeons. The second image of these transplant professionals is that of a mixed reception, as a combination of savior and mercenary. At various times it is equally frustrating to see the recipient's family members as often looking at these doctors with some self-doubt. Unlike other physicians, the problem of a transplant specialist is double-edged which induces multiple conflicts and stress. They have become a sensitive agency in the whole process of transplantation. The problem gets aggravated with the commoditizing of organ transplant process which incurs very high monetary demands. Along with this situation, 
the shortage as compared to the demand makes receivers skeptical of the process and dismissive of the doctors as savior at all.

It is not without any hindsight that medical language is itself made complex. For a sensitive process such as organ harvesting or for that matter any medical procedure, the language is twisted and reshaped so that the other psychological responses or influences get dissolved or even reduced if it cannot be altogether eradicated. With the already acquired threat for the transplant professionals, it is indeed necessary to use metaphors, images, or even symbols. While the other physicians do use a medical register to communicate the medical problems and also for deployment of various medical procedures which otherwise sound horrific, crude and not easily comprehensible for the people. Also, such a means helps the physicians to adopt the objectivity required for the profession. Studies show that amidst the confused and tense moments most often the doctors use a language that is derogatory, combining a sense of humor directed at patients or fellow medical professionals that lightens their mood as well as dissipates the frustration of their lives. Differently seen, a need to use a language of metaphors as such becomes important as it hides the patient from knowing he is being laughed at. For a complicated process like organ harvesting that incites criticism from many levels of knowledge and meaning making within our contemporary culture, it is not only forceful but a useful tool for the continuation of its practice. Mostly, organ harvesting is promoted in the language of 'greenery', 'waste metaphor', 'commodification' and as 'gift metaphor' and mechanical metaphors like 'machine parts'. This allows in the smooth deployment of organ harvesting which otherwise is a cultural clash in many communities as Wasson's paper 'Scalpel and the metaphor of organ harvesting' suggests. The compelling need in individuals to support for the cause of organ harvest is based on the social responsibility induced through concepts of symbiosis or interanimality echoing Merleau Ponty and evolution theorists or a national consciousness as evoked in blood or organ donation campaigns, or the overbearing fellow consciousness injected by modern medicine. From these representations, a new culture is consciously created that survives on its assumptions of being useful, valuable and altruistic.

\section{c) 'Play of language': Medical register and hospital humor}

As Michel Foucault opines in his essay 'The Birth of the Clinic' (1984), one very 
pertinent use of a jargon has been identified as a forthright stress reliever, while at other times it may include different ways of biomedicine to control, discipline and monitor, contain and present the body as subject of research and achieve a complete knowledge of the body. Naturally, this language of control requires a medium of dehumanizing and objectifying project. A language of the normative world would bring in untoward hostility, total disengagement from medical activity altogether which often for a casual person would appear inappropriate, disrespectful, offensive, disciplining, and cold hearted and controlled. ${ }^{14}$ It is also interesting to note that there is a consensus in perceiving the medical jokes as a stress reliever, as a means to express hostility towards patients and co-workers, to express irritation at having to provide useless care or to express social taboos the physicians have to cross during the medical procedure. Hospital humour is very important in the socialization of medical student's too ${ }^{15}$. The circulation of scatological, sexual, gallows oriented ${ }^{16}$ and the usage of dead baby jokes sometimes intended at the patient while at other times intended upon co-workers is a useful example of a stress reliever or contempt at providing useless care to chronic sick patients. E.g. 10th floor transfer-dying (floor number is always the next number on from the highest floor in the hospital) or AGMI - Ain't Gonna Make It (won't survive). Sometimes they are used to mystify medical conditions. Many a times, the jokes and the slanderous words seek to subvert the ideologies of normative world by asserting on the uncontrollability of the body. E.g. Albatross - chronically ill patient who will remain with a doctor until one or other of them expire or Amyoyo syndrome - Alright motherf*****, you're on your own (seen in head injury patients in Intensive Care); there will be no miracle recovery ${ }^{17}$. As seen throughout, the medical jargon becomes a distorted, ambiguous and confusing item that distances the people and plays in order to demystify the human body and lower it to an object for examination, scrutiny and alteration. One key example is the process of organ harvesting. Traditionally, this idea is very much a taboo and at the same times a breach of religious, and cultural values. But the language of organ harvesting emanates and aids in the reconsideration of organ donation/tissue transfer process, cutting out the ethical and cultural preoccupation including the social and religious aspects. This effect upon the readers or viewers to Lee Byron Jennings, comes from the 'double effect' while in the opinion of Frances $\mathrm{S}$ Connelly, the same is termed to be evoking 'multiple perspectives/partial vision' of an image, event or performance. The ancient concerns of embodiment are rewritten, making bodies permeable, boundary less and transferrable. The old notion of self and 
the other becomes an ambiguous entity making the readers respond to it with horror, cynical laughter and anxiety. These novels, work as a counterculture to this ideology and challenge the constricted ideologies of integration and uniqueness of bodies, playing through a medical carnivalesque of surgical intervention and immunosuppression. This propensity also projects how the process of transfer gets deployed both culturally and socially. Unlike the inherited prejudices and taboos of body fragmentation, the process encourages viewing bodies and its parts as valuable commodities that sound valuable, commercial and capitalistic. Most often language aids in this process by dehumanizing the body and segregating them into categories that are interchangeable. The metaphorical application of various body parts as gifts or mechanical parts or as harvest material and waste symbolically enters into the language of culture paving ways for its deployment. This imagination therefore calls for a psychological 'play', a play that is rooted in the past, present and future as an evolving process. The roles and functions of the grotesque mode in the novels aids in an aesthetic subversion to the restrictions imposed on the problem of organ harvesting. e.g. for such a commodification is the usage of words like Bagged and Tagged (B\&T) - Body ready for dispatch to morgue. The trauma of the recipients of organ harvesting is mostly psychological that is informed by the fear of a cultural understanding of 'identity'.

Studies by scholars like Lesley Sharp (Bodies, Commodities and Biotechnologies) indicate that in many cultures of the world, like the Indian and Malay, the religious practices teach that the body is seen as an integral whole, one that hosts the spirit or 'atman' (Sanskrit for soul). When the body is disassembled, it brings a clash in the concept of the spirit or 'atman' merging with another. This idea incites a trauma and fear which get manifested in the form of narratives that speaks of spirits of the donor haunting the recipient and so on, like in Unwind. Neal Shusterman takes recourse in this idea as the characters are forced to harvest and elaborate on the conflict and trauma which the recipient experiences while accepting a donated organ. However, Western concept completely sidesteps this idea and therefore there is more deployment of organ harvest process. Any which way, seen from a cultural angle, organ harvesting narratives (urban legends) are an unconscious manifestation of primal characteristics that chants about survival of the fittest strategies in the event of dearth of organs. 


\section{Conclusion}

In this way, having the 'appeal of a story, a foundation in actual belief and various meaningful messages' medical thrillers contain the cultural warnings or 'poetic justice', suggesting metaphorically or symbolically deeper criticisms of human behavior or social conditions which explains its wide readership. By being 'lively and factual' like their counterparts, urban legends, they work hand in hand to provide meaningful insights into our past, present and future indicating how far we are removed from our ancestors. Whether these novels are an escape from reality, or a desire to validate cultures ideal to answer unusual happenings in the world, they still are consumed by the public for their panoramic angle which they project through grotesque. The predominant function and significance of these fictions, is to satisfy a need for a hint of rational explanation for occurrences along with a conclusion as is assumed of any anxious story telling. The works can be interpreted as a reassurance of the co-existence and struggle of ethical versus unethical ideologies in an attempt to bring harmony and stability to life.

Further, at the psychological level, it comes through that the medical thriller is a suggestion of the 'play' of its past, present and a future which is rooted in the inherent primal characteristics and continues to be a concern even after centuries of progress. The grotesque mode therefore accounts to represent the counterculture of scientific reason and objectivity deriding the inherent human nature as a muddle of primal characteristics. Insisting on the indicated visions or perspectives, these fictions elicit multiple ambiguous, contradictory responses in the reader without raising judgments. On the other side medical thriller is a critique as well as an acknowledgement of the potential of the medical world. Such a space helps to rethink of 'the scientificity of science $^{, 18}$ in a different light. It is rather a platform to accept, analyse and also critique the productive forces of scientific rationality of organ transfer and prevailing medical culture. The grotesque in medical thrillers, seen from this perspective, seeks to represent the multiple sides of organ harvest process. This representation is conveyed through metaphorical, symbolic and emotional responses engaging the reader to participate in this fictive world not to be carried away by a reductionist moral lens as critics on ethics or literature present. The significance of medical thriller lies in its various representations that engage with the contemporary notions of the body and medical culture, which bridges to give the unbiased eye of an aesthetician, to ponder over the various ideologies that are dismissed or not seen within our contemporaneity. 
By differing on Altman's suggestion that "genre study serves to convince theorists that genres actually exist, that they have distinct borders, that they can be identified, they operate systematically, that their internal function can be observed and scientifically described and that they evolve according to fixed and identifiable trajectory," (Altman 1999) this discussion concludes that grotesque mode in medical thrillers establishes its evolving meanings according to cultural values and is an important source of cultural values indicating presence of marginalized categories and stressing on the world as a play of all categories. Not just that they are a repository of manifested collective unconscious anxiety of the popular imagination. In keeping with our desire to know and understand bizarre, frightening and potentially dangerous or embarrassing events that may or will happen and also gratify this need, the medical thriller is a significant genre and a culture of its own. To conclude, the grotesque and the play enunciate and concretize the paradox and psychological confusion associated with modern medical culture. The grotesque-play is a grappling with the internal conflicts and projected as grasping an entertainment of ambiguity and contradiction. The distorted medical world therefore engages and moves the reader to an affectation of disgust, repulsion, anxiety and fear. The distorted relationship seeks to speak of the modern irony of alienation, selfishness and individualism that outstrips all the other concerns. The focus on the breaching of altruism helps to map the pattern of an industrialized culture where economies are more predominant for any sort of sustainment which lurks under the veil of philanthropic.

\section{Notes}

1. Refer 'Medical Thrillers: Doctored Fiction for Future Doctors?' Charpy, J. J Med Humanities (2014) 35: 423. doi:10.1007/s10912-014-93055

2. Refer Catherine Belling's essay on 'The Living Dead: Fiction, Horror and Bioethics' point 1 and 2 - discussions about the medical thrillers as an inquiry into bioethical issue and low literature are charted out.

3. http://bigthink.com/hybrid-reality/is-reality-real,read this for more ideas on 'Is reality real' by Ahmed El Hady

4. Geoffrey Harpham's 'The Grotesque: First Principles' which in fact reinstates this fact: 'Perhaps we should approach the grotesque not as a fixed thing, but as an aesthetic orphan, wandering from form to form, era to era.'(461)

5. Lee Byron Jennings discusses the combination of heterogeneous elements in the grotesque body in detail in The Ludicrous Demon - Aspects of the Grotesque in German PostRomantic Prose (1963). Jennings stresses that while the grotesque form always displays a 
"union of disparate parts" (Jennings 9) it is crucial that "it is not an entirely random distortion ... nor even one aimed at merely altering the human form'. According to Jennings, the grotesque form 'always displays a combination of fearsome and ludicrous qualities-- ... it simultaneously arouses reactions of fear and amusement in the observer' (Jennings 10)

6. Grotesque is "the mixture of heterogeneous elements, the confusion, the fantastic quality, and even a kind of alienation to the world" (Kayser 51)

7. See, 'Organ Theft Narratives'. Author(s): Veronique Campion-Vincent. Source: Western Folklore, Vol. 56, No. 1 (Winter, 1997), pp. 1-37. Published by: Western States Folklore Society.

8. Here 'body' is used as a pun for social structures like medical institutions and the physical body. Prefix-1. diseased, abnormal, or faulty: dysentery, dyslexia 2. difficult or painful: dysuria 3. unfavourable or bad: dyslogistic, Word Origin -via Latin from Greek dus. 'dys'- Collins English Dictionary - Complete \& Unabridged 10th Edn. Harper Collins Publishers. 2 Aug. 2016. < Dictionary.com http://www.dictionary.com/browse/dys->.

9. Refer, Rose, Nikolas and Carlos Novas. 'Biological Citizenship.' Global Anthropology. Editors: Aihwa Ong and Stephen Collier. Blackwell, 2003.

10. Robin Cook's interview by Jay Mac Donald 'I think of myself more as a doctor who writes, rather than a writer who happens to be a doctor'.https://bookpage.com/interviews/8111robin-cook\#.V8e 51uF7JI

11. That which “unhomely”-http://web.mit.edu/allanme/www/freud1.pdf

12. Buklijas, Tatjana. 'Cultures of Death and Politics of Corpse Supply: Anatomy in Vienna, 1848-1914.' Bulletin of the history of medicine 82.3 (2008): 570-607.PMC. Web. 2 Aug. 2015

13. 'Shamanism in the Celtic world' by Corby http://www.druidry.org/library/members- articles/shamanism-celtic-world

14. Refer Lisa Gabbert and Antonio Salud essay 'On Slanderous Words and Bodies out of Control' The Body in Medical Culture. Edited by Elizabeth Klaver. (2009)

15. Genevieve Noone Parsons, Sara B.Kinsman, Charles L. Bosk, Pamela Sankar, and Peter A. Ubel, 'Between Two Worlds: Medical Student Perceptions of Humour and Slang in Hospital Setting,' Journal of General Internal Medicine 16(2001):544-549.

16. 'Gallows humour in hospitals 'can help doctors and patients feel better' http://www.dailymail.co.uk/health/article-2042459/Gallows-humour-hospitals-helpdoctors-patients-feel-better.html\#ixz 4G9UvDtXo

17. Urban Myths- 'Doctors' Slang, Medical Slang and Medical Acronyms and Veterinary Acronyms \& Vet Slang' http://messybeast.com/dragonqueen/medicalacronyms.htm 
18. Refer, review of 'Derrida on Religion: Thinker of Difference' (2014) by McCance Dawne, Routledge.

\section{References}

[1] (n.d.). Doctors' Slang, Medical Slang and Medical Acronyms, Veterinary Slang, Veterinary Acronyms Retrieved August 05, 2016, from http://messybeast.com/dragonqueen/medical-acronyms.htm

[2] Gallows humour in hospitals 'can help doctors and patients feel better (2011) Health Retrieved June 10, 2016, Retrieved June 10, 2016, from http://www.dailymail.co.uk/health/article-2042459/Gallows-humour-hospitals-helpdoctors-patients-feel-better.html\#ixz 4G9UvDtXo

[3] Altman, R. (1984) A Semantic/Syntactic Approach to Film Genre. Cinema Journal, 23(3), 6-18. doi: 1. Retrieved from http://www.jstor.org/stable/1225093 doi:1

[4] Belling, C. (2010) The Living Dead: Fiction, Horror, and Bioethics. Perspectives in Biology and Medicine, 53(3), 439-451. doi:10.1353/pbm.0.0168

[5] Brunvand, J. H. (1981) The Vanishing Hitchhiker: American Urban Legends and Their Meanings, New York, Norton. [Kindle version] Retrieved from https://read.amazon.in

[6] Buklijas, T. (2008) Cultures of Death and Politics of Corpse Supply: Anatomy in Vienna, 1848-1914. Bulletin of the History of Medicine, 82(3), 570-607.Retrieved August 8, 2015. doi:10.1353/bhm.0.0086

[7] Campion-Vincent, V. (1997) Organ Theft Narratives. Western Folklore, 56(1), 1. doi: $10.2307 / 1500384$

[8] Chan, S. (2009) More than cautionary tales: The role of fiction in bioethics. Journal of Medical Ethics, 35(7), 398-399. doi:10.1136/jme.2009.031252

[9] Chao, S. (2010) Rethinking the Concept of the Grotesque: Crashaw, Baudelaire, Magritte, London, Legenda.

[10] Charpy, J. P. (2014). Medical thrillers: doctored fiction for future doctors? Journal of Medical Humanities, 35(4), 423-434.

[11] Collier, R. (2012). Professionalism: The view from outside medicine. Canadian Medical Association Journal, 184(12), 1347-1348. doi:10.1503/cmaj.109-4257

[12] Connelly, F. S. (2014) The Grotesque in Western Art and Culture: The Image at Play, 62. Cambridge, Cambridge University Press.

[13] Connelly, F. S. (Ed.) (2003) Modern Art and the Grotesque, Cambridge, Cambridge University Press.

[14] Cook, R. (1977) Coma: a novel, [Kindle DX version] Available from: https://read.amazon.in/

[15] Freud, S. (2003) The Uncanny. London, Penguin Publications 
[16] Gerritsen, T. (2010) Harvest, [Kindle DX version] Available from: https://read.amazon.in/

[17] Goldstein, J. H. (1998) Why We Watch: The Attractions of Violent Entertainment, Oxford, Oxford University Press.

[18] Harpham, G. (1976) The grotesque: first principles. The Journal of Aesthetics and Art Criticism, 34(4), 461-468.

[19] Harpham, G. G. (1985) On the Grotesque: Strategies of Contradiction in Art and Literature, The Davies Group Publishers.

[20] Ingold, C. (2015, February 28). Druid Grove, Order of Bards, Ovates and Druids. Retrieved August 05, 2016, from http://www.druidry.org/

[21] Jennings, L. B. (1963) The Ludicrous Demon: Aspects of the Grotesque in German Post-romantic Prose, Berkeley, University of California Press.

[22] Kayser, W. (1981) The Grotesque in Art and Literature. New York, Columbia University Press.

[23] Klaver, E. (Ed.) (2009) On Slanderous Words and Bodies Out of Control. The Body in Medical Culture, New York, University of New York Press.

[24] Lupton, D. (2003) Medicine as Culture. London, Sage Publications

[25] Masser, B. M., White, K. M., Hyde, M. K., \& Terry, D. J. (2008) The Psychology of Blood Donation: Current Research and Future Directions. Transfusion Medicine Reviews, 3(22), 215-233.

[26] Miller, J. (2015) Passionate Virtue: Conceptions of Medical Professionalism in Popular Romance Fiction. Literature and Medicine, 33(1), 70-90. doi:10.1353/lm.2015.0010

[27] Parsons, G. N., Kinsman, S. B., Bosk, C. L., Sankar, P., \& Ubel, P. A. (2001) Between two worlds. Journal of General Internal Medicine, 16(8), 544-549. doi:10.1046/j.15251497.2001.016008544.x

[28] Rose, N., \& Novas, C. (2003) Biological Citizenship. Global Anthropology, Blackwell Publishing, 439-463.

[29] Lupton, D. (2003) Medicine as Culture. London, Sage Publications

[30] Masser, B. M., White, K. M., Hyde, M. K., \& Terry, D. J. (2008) The Psychology of Blood Donation: Current Research and Future Directions. Transfusion Medicine Reviews, 3(22), 215-233.

[31] Miller, J. (2015) Passionate Virtue: Conceptions of Medical Professionalism in Popular Romance Fiction. Literature and Medicine, 33(1), 70-90. doi:10.1353/1m.2015.0010

[32] Parsons, G. N., Kinsman, S. B., Bosk, C. L., Sankar, P., \& Ubel, P. A. (2001) Between two worlds. Journal of General Internal Medicine, 16(8), 544-549. doi:10.1046/j.15251497.2001.016008544.x

[33] Rose, N., \& Novas, C. (2003) Biological Citizenship. Global Anthropology, Blackwell 
Publishing, 439-463.

[34] Russo, M. J. (1995) The Female Grotesque: Risk, excess, and modernity, Psychology Press.

[35] Sabo, P. (2013). Book Reviews/Comptes rendus: Derrida on Religion: Thinker of Differance by Dawne McCance. Studies in Religion/Sciences Religieuses, 42(2), 272273. doi: $10.1177 / 0008429813480927 \mathrm{~g}$

[36] Wasson, S. (2015) Scalpel and Metaphor: The Ceremony of Organ Harvest in Gothic Science Fiction. Gothic Studies, 17(1), 104-123. doi:10.7227/gs.17.1.8 